
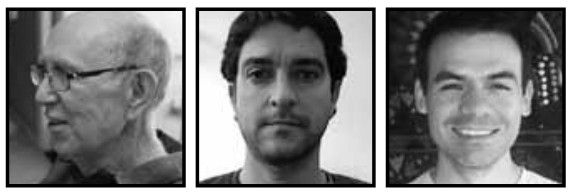

\title{
Commentary
}

\section{Creating Hybrid After-School Enrichment Activities}

\author{
Michael Cole, Robert Lecusay, \& Ivan Rosero \\ University of California, San Diego
}

\begin{abstract}
In this commentary we propose a collaborative strategy for the creation of informal learning activities in after-school settings that are also shared sites of learning, research, and development. We briefly trace the history of a research program- “UCLinks"-whose defining feature is a form of collaboration between institutions of higher learning and local community institutions responsible for youth in the afterschool hours. These collaborations thrive only to the degree that "mutual appropriation" can be negotiated between partners, and it is within mutual appropriation that new possibilities for creative cross-generational and cross-cultural informal learning activities are materialized.
\end{abstract}

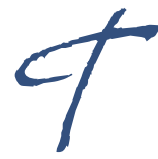

he Laboratory of Comparative Human Cognition's interest in "learning that occurs beyond the classroom" grows out of our long-term interest in the role of schooling in human development. As part of this work, many decades ago we pursued a project in which, in a university setting, we created after-school clubs for children whose behavior was also being observed in their classrooms. We picked the subject matters for our clubs to be attractive to the children and at the same time, allow the adults to try to figure out whether the children learned in a different manner when reading was a means to doing something fun (e.g., being a member of a cooking club where you actually got to bake your favorite cake, or of a science learning activity in which you got to hook up electric circuits). One firm result of that research was that children who were seen as difficult in the classroom were just fine in the after-school club. And vice versa: some children with advanced 
academic skills proved to be so busy stirring up the social pot that the cakes did not get baked (Hood, McDermott, \& Cole, 1980).

Not long after, in the midst of research on ways in which displays of learning abilities are manifested across a range of social contexts, we found ourselves running another after-school club. Its participants were children singled out by their teachers as needing extra help to learn the basics of reading. The overall curriculum we designed consisted of a variety of game-like activities to enable us to assess reading ability while promoting the ability to read. In the course of that program, we began to use then-just emerging computer games to accomplish this purpose. Eventually, computer-mediated activities became central as part of a mixed activity system playworld we called “The Fifth Dimension” (LCHC, 1982).

In designing these after-school activities, we deliberately sought to create alternatives to dominant pedagogical practices that confront children who fail to learn through the standard routines of the classroom. At the time, a great deal of attention was being paid to "quality time on task" and the search for ways to expand "time for learning" during the school day. The favored solution among educationalists was adoption of classroom management techniques narrowly focused on how to get kids spending more time sitting at their desks doing the intellectual exercises that had been organized for them. The archetype social structure of the children's regular classrooms was the "recitation script" in which children are constantly answering known-answer questions posed by the teacher. Our classroom and classroombased research had revealed a little-noticed consequence of this regime, amplified by a focus on creating more time on task. Children in such classrooms are rarely given the opportunity to form learning goals of their own; these goals are prescribed by the teachers and the school district. This same research had also shown that forming goals is central to the process of arranging for learning-with-understanding (Newman, Griffin, \& Cole, 1989).

Consequently, we viewed the opportunity to engage with children in afterschool settings as a research opportunity. In most after-school care organizations, children and youth are freer to choose the activities they engage in and social relations are conducted on a more informal basis. Under such conditions, we could try out really different ways of organizing the teaching/learning process of children who are struggling within the regime of formal schooling.

This was our entering point. If we were self-conscious about the process of inter-institutional collaboration over time, perhaps we could become more intelligent 
about how scarce resources can be deployed more effectively in the name of the next generation's development.

\section{A U-C Link}

We conceive of our model as a U-C Link. It's partly a play on words; we are at the University of California, and we operate by linking ourselves across institutional boundaries to create a common program: A university group and a community group agree to jointly conduct an activity after school. We think of the ideal basic unit of a U-C Link to be:

1. A university course in which students' education is centered around texts and academic discourse.

2. A community setting where a community staff person cooperates with the teacher of the class and together they come up with a plan to supervise the undergraduates and children in educationally productive activities.

3. A system of activities that "fits" with the needs of the University and the Community institution.

In our local University's terms, our after-school involvement fulfilled all three of its touted missions: Teaching, Research, and Service.

1. Undergraduate students obtain the experience of having to confront their classroom-derived book learning with the lives of children on their own local turf, an excellent medium for genuine theory-practice education for the undergraduates.

2. Our specially organized activities in settings such as youth clubs, libraries, churches, and extended day programs have provided us with an excellent research setting for testing out innovative educational ideas.

3. The active participation of supervised and enthusiastic undergraduates, experts in learning, provides a clear service to local community after-school centers, hard pressed for funds for qualified assistance with programming in the after-school hours.

"On-the-ground" initiation of a U-C Link requires that a college or university offer a course, an after-school care provider (a school, a library, a youth club, etcetera) offers space, and staff participate on behalf of the host institution. Together the two parties cooperate to develop the activity they have jointly undertaken. A U-C Link is not designed to be a free lunch-but rather a delicious and nutritious, and very 
inexpensive lunch. If the experiment seems to be working, the partners are likely to need to find resources for a person who worries about the collaboration itself. Continued collaboration becomes an additional common goal among the U-C linked.

\section{The Necessary Hybridity of UC Links Activities}

From our experience, one of the challenges facing the study of learning outside of school is that, unlike schooling with its traditional rules and structures, one faces a wide diversity of institutional settings with an even broader range of goals, rules, regulations, and "ways things should be done." The opposite of "formal" is not "chaos," but a different social order with its own forms, values, and conventions.

In organizing partnerships between colleges and communities, there is a kind of "default localism" in which the norms of each organization are assumed to be more or less "pre-synchronized." "'Sure, it will take some adjusting, but we all want the same thing, so it will work out.") But it is precisely in coordinating disparate aims in a community setting that difficulties arise over time. In our experience, when insufficient attention is devoted to the relationship between organizations, especially how they work out the division of responsibility that accompanies their division of labor, such difficulties can grow to threaten the partnership itself.

The difficulty can be as "trivial" as the fact that the local community organization begins its fall activities when the elementary school opens while the college partner opens a month later. What do you do in the meantime? Or perhaps the university is on a quarter system, or can only run a program four days a week? To community partners, the jolt to programming from the untimely appearance or disappearance of a dozen college students can be severe if it does not become a part of the routine programming.

A similarly "trivial" difficulty can arise if a faculty member who teaches the partnering course takes a sabbatical leave or if there are insufficient funds to conduct the practicum class in a given academic period. How can one's local Boys and Girls Club be expected to organize its programming on the whims of the course schedules of their partnering college?

A quite different, and from our perspective, non-trivial difficulty arises from the enormous power of the public school system to require that students, starting from grade one, do significant amounts of homework each evening. Local community organizations, pressured by the school on one side and worried parents on the 
other, feel bound to provide students with extra time and support for doing their homework. Schools now routinely co-opt students' out-of-school time with kill-anddrill worksheets where after-school activities once could offer a safe harbor from such prescribed tasks.

As a consequence of such pressures, those like ourselves who seek to leverage the potential of informal learning environments to create valuable learning opportunities have had to learn to work with our community partners to find times for genuinely development-enhancing activities to take place.

\section{A Sensibility for Informal Possibilities Within Cross-Institutional Collaboration}

Effective partnerships imply accommodations in both directions. For lack of space, we provide here one recent example that highlights both the mutual appropriation (Downing-Wilson, Lecusay, \& Cole, 2011) between partners, and a specific case of how the resulting new possibilities for informal learning can be brought together in the creation of a novel activity.

In our most recent U-C collaboration at a local community center in southeastern San Diego, undergraduates join in to help children with their homework, and also collaborate with graduate students to ensure interesting enrichment activities are available outside of homework time. In parallel, the community site coordinator helps to create space for special projects and assists with local diplomacy. Once the two organizations get accustomed to each other's rhythms of operation and overriding local necessities, new opportunities for organizing model learning activities are to be found in the odd gaps in schedules, where genuinely new forms of learning experience can be designed.

One such recent experience, dubbed the "Ocean World Activity," took place over two weeks during April 2009, while kids who attended the center were on vacation from school. The activity, which included five local elementary school-aged girls, centered on learning about the ocean, and made available to the kids multiple modalities of engagement: reading from a children's science book, looking up images and facts on the Internet, populating a virtual world with digital content resulting from Internet searches, drawing on poster-boards affixed to the walls, and the use of puppets for make-believe. All of this took place within a specially designated and resource-enriched space known locally as the "tech room." 
There is no space here to do justice to the interactional dynamics and learning strategies that this activity made possible, but it is of central importance to this commentary to foreground the "location" of this informal activity within a set of possibilities that can emerge when institutions collaborate during after-school hours. Many elements were involved here, ranging from the engaged participation of local kids, to the mix of "high" and "low" tech tools used, to the theme of the activity itself (it was a jointly organized visit to the aquarium that put the ocean "in the air"), to the relative expertise of graduate and undergraduate students, and extending even to the fact that this activity took place during vacation time for the kids. The high degree of contingency that can nevertheless be funneled in productive directions, through a kind of sensibility for informal possibilities that develops in time, is one hallmark of this partnership.

Of course, vacation time is not the only time when the informal can be leveraged. Using the power of informality, successful blending activities are a great resource. On a day-to-day basis, arithmetic lessons are folded into cooking lessons, where a notion of fractions takes on multiple meanings, as children need to double the size of recipes, or share 25 cookies among 10 children. This all naturally merges with regular snack time and new experiences of eating vegetables grown in the Center's garden. In turn, the garden provides its own plethora of opportunities to bring the content of the school into the activity as a means to a goal the children are seeking to fulfill. Likewise, outside sports activities are turned relatively easily into elementary mathematics exercises as groups of kids compete to reach the finish line by solving subtraction problems.

\section{Sustaining Quality}

Since we began our research three decades ago, many talented, creative, and persistent people have, for one reason or another, hit upon the U-C Links approach to leveraging collaborations with community-based youth-serving organizations. It is exciting to see programs develop with (relatively) high levels of fiscal support, using digital technologies that attract youth and arguably build just the kind of productive synergy with higher education that we ourselves hope to promote.

However, even as we write, some of the most successful such programs are only now seeking to replicate themselves, responding to the demand to "take it to scale." They have no clear-cut plan of how they will continue to exist once the funding that made their birth possible is gone and they are kicked out of the nest to make their way in the economic landscape of the informal after-school world. 
We offer the UC-links model as one way of accomplishing several goals at the same time.

1. To create social ecologies where kids and college students learn from one another, and where university and community partners meet on relatively "leveled" ground as they learn to look at the world through one another's eyes.

2. To enhance quality of undergraduate education through provision of environments where they can learn about the linkages of their university-based knowledge with the life conditions of the generation coming up behind them.

3. To make it possible for institutions of higher learning to be more effective citizens in their local communities.

In sum, it was known to our grandmothers no less than to John Dewey that, properly organized and supported, learning in informal settings designed to be accommodating to young people can be enormously productive intellectually and socially. But sustaining the infrastructures which make such high quality activities routinely available is a far more difficult task. The basic challenge is a social-organizational matter, not a matter of figuring out how to make stimulating learning environments for children.

As currently constituted, most after-school programs can realistically aspire to providing children with a physically and socially safe environment during the afterschool hours. Without the resources to hire and retain a sufficient number of professional staff, it is unrealistic to expect them to organize activities other than homework help that are designed to significantly supplement the school. A UC-Links program is one way to provide the necessary additional resource enrichment.

Existing proof of successful programs, initiated by a variety of talented scholars, now abounds. Finding ways to make such activities by after-school experience providers a routine social practice is the challenge of the present. 


\section{References}

Downing-Wilson, D., Lecusay, R., \& Cole, M. (2011). Design experimentation and mutual appropriation: Two strategies for university/community collaborative afterschool interventions. Theory \& Psychology, 21(5), 656-680.

Hood, L., McDermott, R., \& Cole, M. (1980). Let's try to make it a good day - Some not so simple ways. Discourse Processes, 2(3), 155-168.
Laboratory of Comparative Human Cognition. (1982). A model system for the study of learning difficulties. Quarterly Newsletter of the Laboratory of Comparative Human Cognition 4(3), 39-66.

Newman, D., Griffin, P., \& Cole, M. (1989). The construction zone: Working for cognitive change in school. Cambridge: Cambridge University Press.

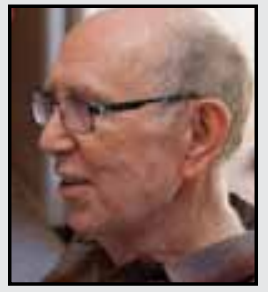

Michael Cole is Professor of Communication and Psychology at the University of California, San Diego where he is the Director of the Laboratory of Comparative Human Cognition. He has conducted cross-cultural research on cognitive development, especially as it relates to the role of literacy and schooling. His recent research has been devoted to a longitudinal study of individual and organizational change within educational activities specially designed for after-school hours. These systems link universities and local communities and allow a study of the dynamics of appropriation and use of new technologies and cultural-historical approaches to human development.

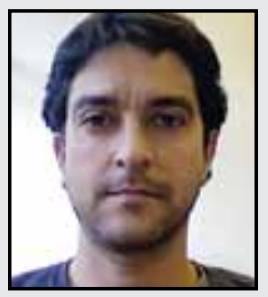

Robert Lecusay is a doctoral candidate in communication and cognitive science at the University of California, San Diego. He is a member of the Laboratory of Comparative Human Cognition where he collaborates with lab colleagues, undergraduates, and members of the local community to create and study after-school learning environments. In these environments he designs and implements innovative science education activities. Adopting a cognitive ethnographic approach, he investigates how the activities and their participants learn and develop over time. 


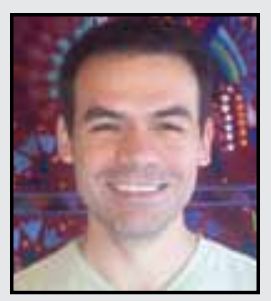

Ivan Rosero is a doctoral candidate in communication, cognitive science, and science studies at the University of California, San Diego. His research focuses on informal learning activities made possible through collaborative partnerships between community and non-community institutions. Expansive collaborations that lead and call for reciprocity, dialogue, and mutual investment simultaneously create their own forms of life and vital needs. Expressed within joint activity, these forms of life link imagination, affect, play, and learning on the one hand, and ongoing negotiation across institutional boundaries on the other. The complex entanglement across time between these linkages is the central focus of the research.

LINKTO:

www.uclinks.org 